\title{
Student Perceptions of a Simulated Clinical Experience: A Pilot Study
}

Haley Elliott

University of Central Missouri, hmc98450@ucmo.edu

Klaire Brumbaugh

University of Central Missouri, brumbaugh@ucmo.edu

DOI: https://doi.org/10.30707/TLCSD5.1.1624982519.538001

Follow this and additional works at: https://ir.library.illinoisstate.edu/tlcsd

Part of the Scholarship of Teaching and Learning Commons, and the Speech Pathology and Audiology Commons

\section{Recommended Citation}

Elliott, Haley and Brumbaugh, Klaire (2021) "Student Perceptions of a Simulated Clinical Experience: A Pilot Study," Teaching and Learning in Communication Sciences \& Disorders: Vol. 5: Iss. 1, Article 7. DOI: https://doi.org/10.30707/TLCSD5.1.1624982519.538001

Available at: https://ir.library.illinoisstate.edu/tlcsd/vol5/iss1/7

This Student Voices is brought to you for free and open access by ISU ReD: Research and eData. It has been accepted for inclusion in Teaching and Learning in Communication Sciences \& Disorders by an authorized editor of ISU ReD: Research and eData. For more information, please contact ISUReD@ilstu.edu. 


\title{
Student Perceptions of a Simulated Clinical Experience: A Pilot Study
}

\begin{abstract}
Purpose: The purpose of this qualitative study was to document the experience of using a computerbased simulated (Simucase, 2019) learning opportunity in a Master of Science in speech-language pathology program.
\end{abstract}

Method: Focus groups were held utilizing a semi-structured interview format. Themes were identified using a qualitative methodological approach. Participants were first year graduate students $(N=10)$ that were interviewed after completing an eight-week simulated learning opportunity.

Results: Seven themes emerged from the data. The themes were as follows: setup of the computer-based simulation, the incorporation of computer-based simulation in courses, supplemental information that assisted in development of clinical knowledge, increased knowledge of assessments and testing procedures, authenticity, confusion regarding feedback and how to benefit more from computer-based simulation.

Conclusions: Results were consistent with previous literature in simulated learning. Students reported positive and negative feelings regarding the computer-based simulated experience. The simulated learning experience resulted in overall positive perceptions for using stimulation to improve familiarity with assessments and understanding testing procedures.

\section{Keywords}

computer-based simulation, simulated learning, speech-language pathology

\section{Cover Page Footnote}

Thank you to Jaclyn Brandhorst, PhD, for her contributions and assistance in developing the interview guide. 


\section{Introduction}

In the field of speech-language pathology (SLP), graduate students are required to obtain a minimum of 400 clinical hours to be eligible for certification upon graduation. For many students, obtaining these clinical hours takes place in on-site settings, such as on-campus speech and hearing clinics, or off-site settings, such as private practices or hospitals. It is common practice that students participate in a collection of clinical assignments at an on-site clinic with the final semesters spent completing practicums at off-site locations. The 2020 American Speech-Language-Hearing Association (ASHA) certification standards allow for a maximum of $20 \%$ of clinical hours to be gained through simulated experiences (ASHA, n.d.-b). The purpose of this qualitative, phenomenological study was to determine students' perceptions of a computer-based simulated experience to gain clinical hours and experiences. Students' perceptions may have the ability to impact the utilization of future simulated experiences and the associated teaching methods used in conjunction with the simulation.

Clinical simulations can include standardized patients, virtual patients, digitized mannequins, immersive reality, and task trainers (ASHA, n.d.-b). Standardized patients are hired individuals that play the role of having an illness (Ha, 2018). This simulated experience allows for human interaction and for the practicing student to gain more information about the client through faceto-face communication (Foley et al., 1997; Wildman \& Reeves, 1997). Virtual patients are defined in many ways throughout the literature but are most commonly reported as being a computer-based patient with real-life health concerns (Ellaway et al., 2008). Digitized mannequins, often referred to in the literature as Human Patient Simulators (HPSs), are full body computerized mannequins that are programmed to represent varying genders, ages, and health conditions (Nehring et al., 2002). Immersive reality is the concept of using projectors and specialized liquid crystal display glasses to immerse a student into a health scenario through a simulated reality. An example of this would be the use of a cave automatic virtual environment (CAVE) to place nursing students into virtual realities (William et al., 2008). These realities often also incorporate the use of HPSs (William et al., 2008). Task-trainers are utilized to help students focus on one specific skill to master in isolation. These trainers typically do not involve any feedback from the simulated client (Johns Hopkins Medical Simulation Center, 2018). The prevalence of simulation is growing in the field of speech-language pathology. In a 2018 study by Dudding and Nottingham, $51 \%$ of responding institutions reported using a computer-based simulation, such as Simucase (2019).

Simucase (2019). Simucase (2019) is a computer-based simulation that allows students to complete clinical assignments independently and asynchronously from the clinic or course experience. Currently, the program includes simulated experiences for speech-language pathology, audiology, and occupational therapy. The platform allows members to access parttask trainers, assessments, and intervention sessions. The user can practice working with a client, family members, and other professionals through the case history and collaboration aspect. Students work through the following steps with a virtual client: case history, collaboration, forming a hypothesis, determining and administering assessments, formulating a diagnosis, and providing recommendations (Jansen et al., 2015) in learning or assessment mode. Jansen and colleagues also reported that members receive feedback and are allowed unlimited practice trials through the learning mode. Assessment mode does not provide feedback as the user is working 
through the case. Students must achieve a score of $90 \%$ or greater in order to count the minutes towards the 400 clinical clock hours required to obtain a certificate of clinical competence from ASHA. However, the Simucase (2019) platform allows for repeated practice in learning and assessment mode to achieve mastery.

Simulation research. Simulation research has a rich history in the field of nursing and medical professions due to the application of experiential learning where the student is engaged in learning by doing (Howard, 2011). Kolb and Kolb (2005) stated that the Experiential Learning Theory focuses on the idea that students learn best through practice of real-world scenarios that coincide with those they are learning about in the classroom. Problem-solving, decision-making, and reflection are key components of cognitive development according to John Dewey (Kolb, 2005). Adding these components to the education of service-learning professions, allows individuals to apply and relate abstract concepts in real-time (Howard et al., 2011). Simulation is a tool that enhances real experiences during the training process to teach technical and foundational skills, problem-solving, and team-based communication (Lateef, 2010). In the field of speech-language pathology, the use of simulation has been evaluated for treating dysphagia with positive results on the student's self-confidence, anxiety, and preparedness (Miles et al., 2016; Ward et al., 2015). A recent systematic review of high-fidelity simulation in nursing provides evidence that simulation improves student self-confidence (Labrague et al., 2019). The use of simulation offers an alternative way to practice clinical skills while maintaining patient and student safety (Lateef, 2010).

In addition to protecting the patient, the incorporation of simulation is a valued experience from a clinical teaching and learning perspective. While engaging in simulated learning experiences, students can repeatedly practice a skill until mastery. Repeated practice has been shown to be an effective teaching method as it improves student confidence and improves knowledge and performance (Cummings \& Connelly, 2016; Fitzgerald et al., 2017; Scherer et al., 2016). Student confidence and improved knowledge and performance was explored by Ellis (2017) in the field of speech-language pathology. The author aimed to describe students' perceptions of the effectiveness of a simulated clinical experience. Results were indicative of overall positive experiences for students. However, one weakness that was noted in this study was that critical thinking could not be measured during a virtual experience. A second qualitative study by Bressmann and Eriks-Brophy (2012) indicated students positively described experiences with simulated patients. Students reported clinical skills to have been enhanced through classroom teaching and lectures and cemented by simulated experiences (Ward et al., 2015). A recent mixed-methods study by Clinard and Dudding (2019) identified quantitative and qualitative themes regarding the use of Simucase (2019) in communication disorders programs. Their themes revealed strengths and weaknesses in the domains of communication, skill practice, technology, and independent learning.

Although simulated experiences are approved for clinical hours, and many schools have adopted the practice, there are unknown factors related to the educational process. Like other clinical experiences, ASHA requires a minimum of $25 \%$ supervision. In simulated experiences, the supervision may occur asynchronously and virtually (ASHA, n.d.-b), but there is limited information regarding best practices for prebriefing and debriefing to achieve maximal student outcomes. A critical review by Sawyer and colleagues (2016) described multiple types of 
debriefing methods utilized in healthcare simulation. However, a specific pre-brief and debrief approach has not been required for communication disorders programs. ASHA states that the debrief may include "face to face discussion, self-reflection with feedback, and/or written selfevaluation with feedback" (ASHA, n.d.-b), but ASHA does not provide guidance on the pre-brief process. There are many factors that determine the effectiveness of computer-based simulation within CD programs. Due to many of these factors still being unknown, the purpose of this study was to determine specific factors that students perceived were the most and least effective.

\section{Method}

To provide students with experience administering screening and assessment procedures, the communication disorders program in this study implemented a summer clinical experience focused on child language assessment via a computer-based simulation (Simucase, 2019). Both authors were users of the Simucase platform, but they were not affiliated with Simucase. The experience took place during the eight-week summer, 2019 semester and fulfilled one clinical practicum placement. The primary investigator $(\mathrm{PI})$ is a graduate student, a peer to the participants and was also enrolled in the simulation experience. To reduce bias, the interview guide was created by a colleague that was not involved in the simulation-based educational project. In addition, the authors engaged in reflective practice by meeting weekly to discuss observations and emerging results. The opinions and experiences of the authors were not included in the data collection.

Research design. The current qualitative study was approved by the university Institutional Review Board. A phenomenological approach (Carpenter \& Suto, 2008) was used to determine students' perceptions of a simulated clinical experience. This phenomenological study provided students the opportunity to utilize personal knowledge and interpretations to reflect on their experience. The descriptive research approach was chosen to allow insight into students' motivations and actions through focus groups. The PI held two different focus groups with a total of 10 participants. One focus group contained four students, and the other contained six.

Simulated experience. During the simulated experience, students completed simulations including part-task trainers and assessments with an emphasis on child speech and language disorders. Students completed eight cases totaling nine hours and 45 minutes of simulated experience.

In addition to the simulated experience, students were exposed to psychometric properties terminology during the weekly meetings as part of the pre-briefing component. The instructor provided lectures that were presented in a conversational manner. Upon completion of the lectures, students were tasked with completing a partner-project involving researching properties of various assessments. Each student was provided a table to guide the exploration of psychometric properties (Brydon, 2018). The table included the following psychometric properties that each student pair was assigned to research: inter-examiner reliability, test-retest reliability, construct validity, concurrent validity, normative sample, test norms and derived scores, sensitivity, and specificity. During the weekly meetings, student pairs took turns presenting findings to their peers for the assessment that corresponded to the simulation case. 
Participants. All participants were first (G1) or second semester (G2) graduate students at a rural, residential, public graduate school in the Midwest. They were enrolled in the eight-week simulated learning experience during Summer, 2019. The G1 students were only enrolled in the clinical practicum and the G2 clients had one other client experience during the summer. The age of participants ranged from 20 to 39. Ninety percent of participants were female, which is representative of the field of SLP as it is primarily female dominated (ASHA, 2016b).

Participants were recruited for the study in the semester following the completion of the eightweek simulated experience. Recruitment took place through an invitation via email sent by the PI. At the beginning of each focus group meeting, participants voluntarily consented to participation with audio and video recording. Participants were informed of the potential risks and reminded of their right to withdraw from the study at any given time without consequences.

Data collection. The interview guide was created by the second author and a colleague with experience in qualitative research methodology. The interview guide consisted of three parts: (1) General Perceptions of the Course, (2) The Simucase (2019) Experience, and (3) Perceived Learning as a Result of Simucase (2019). Within each of the primary categories, in-depth questions were asked to gather detailed descriptions of individual experiences following a semistructured interview process (Carpenter \& Suto, 2008). The focus groups were recorded on the clinic's clinical observation recording system (CVI, 2017) and audio via cellphone for transcription purposes.

Interview procedure. Experiences, attitudes, and concerns were captured through a semistructured interview style using focus groups (Carpenter \& Suto, 2008). The focus groups met for approximately 45 minutes each in a large therapy room in the university speech and hearing clinic. Participants were seated face-to-face around a table. As the PI asked questions from the interview guide (Appendix A), each participant was provided an opportunity to respond. Each focus group chose the order in which each person would respond. One focus group elected to go around the table and give each person a chance to speak, while the other focus group decided to respond to questions conversationally, feeding off one another.

Data analysis. Following the completion of each focus group meeting, the PI completed the transcription process. Although bias was unable to be completely removed due to the involvement of the authors in the experience, the following process was utilized. This process involved the assignment of de-identifying codes to each participant to encourage anonymity. From there, each member of the two focus groups was asked to participate in member checking (Carpenter \& Suto, 2008). Member checking is an important aspect of qualitative research, as it allows the participants to review their contribution and observe how it will be used in the research process (Carpenter \& Suto, 2008). All participants were emailed a copy of the focus group interview transcription to read through and review. This process allowed participants to ensure opinions were portrayed accurately. All ten participants responded via email that they agreed with the transcripts indicating $100 \%$ reliability. The transcriptions were then coded using a line-by-line approach (Glesne, 2016) and reviewed multiple times. A color-coding system was used to visualize the data. This approach allowed the data to be mapped into similar groups. The authors met weekly to discuss emerging codes and themes by reading aloud statements and discussing the potential themes until agreement was reached. The codes were transferred into themes using a coding process where direct quotes were grouped into separate pages based on 
keywords or concepts. Common feelings and opinions determined the themes. The themes with similar underlying meanings or messages were combined into larger, more inclusive categories. For the themes reported, there was agreement among the focus group members.

\section{Results}

The most significant themes identified through data collection included the setup of the computer-based simulation, the incorporation of computer-based simulation in courses, supplemental information that assisted in development of clinical knowledge, increased knowledge of assessments and testing procedures, authenticity, confusion regarding feedback and how to benefit more from computer-based simulation.

Setup of the Computer-Based Simulation. The participants reached consensus that the learning mode aspect of Simucase (2019) was highly beneficial. Participants liked the fact that they could attempt the case as many times as needed without their grade being affected. Multiple participants stated they benefited from being provided a portion of the assessment manual for each case.

The asynchronous accessibility of Simucase (2019) was a common comment by all participants. One respondent provided the following opinion:

It's something you can do on your own time. We are so busy here with so many other things anyway, it's nice to be able to sit at home, still be working, but in your own chair. According to the Simucase (2019) user guide, the application was designed so that users could start and stop a case at any given time, and their progress would be saved (Johnson et al., 2019).

Incorporation of the Computer-Based Simulation in Courses. Overwhelmingly, all participants agreed that the incorporation of Simucase (2019) could be beneficial in each course. Participants indicated that the exposure of working through a case that applied to what was being taught in courses would provide more concrete learning. One participant stated:

I think I agree that each class that we are in should have at least one Simucase experience in it.

Another participant stated the following:

Even preparing for our competencies. That [using Simucase (2019)] would be beneficial.

Supplemental Information That Assisted in Development of Clinical Knowledge. Students reported positive experiences towards the learning opportunities that occurred in conjunction with the simulated evaluations. These experiences included prebriefing and debriefing and exploration of psychometric properties. There was widespread agreement by participants stating that the debriefing portion of the experience allowed for them to discuss their questions and bring them to the attention of the clinical instructor. One participant stated the following:

The weekly meetings definitely helped being able to discuss what the previous week brought and what the upcoming week will be.

Another participant reported:

I think it was nice to be able to talk about the tests in depth and their purpose and why we would give that test. And be able to apply it past the simulation and into our actual clinical experience. 
Increased Knowledge of Assessments and Testing Procedures. The participants agreed that their confidence in testing procedures increased following the Simucase course experience. Each assigned case involved the completion of a part-task trainer or a full assessment. Students were encouraged to print off the protocol, provided through Simucase, and score the assessment while working through the case. This allowed students to practice completion of the protocol, along with scoring procedures. Participants used terms like "felt comfortable," "feel better," and "confident" when reflecting about their knowledge in selecting, administering, scoring and interpreting assessments as stated by the following:

I'm confident picking out the right assessment and giving the assessment.

Followed by another participating stating:

I definitely feel like I can give the test and score and do all that better now.

Another participant commented on the improved confidence in interpreting scores:

It increased my confidence in being able to interpret scores.

Graduate students are exposed to various assessments in their clinical practicums and courses. The participants agreed that at least one assigned assessment was new to them. All participants felt the exposure to assessments that were new to them was beneficial. One participant stated the following:

I also liked having experience with assessments that we don't typically give. Actually, one of the assessments that we did on Simucase, I gave to one of my clients this semester because I had experience with it.

Another stated:

It gave me more ideas of tests to give. I don't have to just stick to what I've learned in class or what I've seen used around here most often. I can get outside my comfort zone and give things that are more beneficial to my client.

Authenticity. Each Simucase (2019) case allows the participant to complete the case in learning mode and assessment mode. In learning mode, the program provides feedback for each response selected. The feedback is provided by pop-up messages stating your clicked response was either correct or incorrect. In learning mode, the participant is not docked points for selecting the wrong response. Because of this, participants admitted that they utilized learning mode to click through each response in order to be provided with the correct ones. There was overwhelming agreement of participants stating that they had done this for at least one portion of a case, and all agreed that it was a result of frustration with the program. All participants agreed that the case history portion resulted in the most frustration, leading to the most nonspecific clicking.

Another finding was that most participants reported that there was a lack of behavioral modifications incorporated into the cases. Participants indicated this was not authentic, as many younger clients may present with behavioral concerns in person. One participant reported:

I wish Simucase had more behavioral things though. Like modifications. Because when you're thrown in there with your real kiddo it's a completely different world. It's not just the testing. It's dealing with a little person and that doesn't always go as planned. So, maybe more sequencing of sessions on there instead of just the assessment. Behavior modification would be nice. 
This was followed by another participant stating:

I also liked when they had the real people better as opposed to when the simulated people or the computer voice people. The real people makes it a lot more... I guess interactive isn't the right word, but real life.

Confusion Regarding Feedback. All participants indicated the feedback provided was not beneficial. It was stated by numerous participants that Simucase (2019) would mark something as incorrect but would not give reasoning. This resulted in confusion for many, as they felt their response should have been correct, or were unsure as to why another response was more accurate. One participant reported the following:

When you're G1 or G2 and you don't know anything about these assessments, it would be nice to know why it's [your response] wrong.

Another participant stated:

It was like a puzzle trying to figure out which ones [answers] they wanted.

Some assessment subtests required a typed response for points. Participants stated the typed responses provided no feedback. This resulted in some stating they simply typed something just to receive credit for the question, as one participant stated below:

It kind of made it not worthwhile... just receiving credit for typing in a box.

Similarly, a participant agreed and stated the same thing happened during the hypothesis portions of cases. It left them confused and wondering whether they were on the right track with the entire case itself. Participants suggested Simucase (2019) could provide learners with a list of possible correct answers to allow them to compare their response to what Simucase (2019) suggested. One participant stated the following:

With the written responses even giving you some acceptable answers to see how close yours were to it.

How to Benefit More From Computer-Based Simulation. Participants were asked what advice they would pass on to future students participating in a Simucase (2019) experience. Participants agreed upon the following advice: Start early, take notes, and practice in learning mode as much as you can. Participants also reported that although you can click through responses to get through the case faster, it is not beneficial, and you do not take away as much information. One participant reported:

Read the booklets [manuals]. Like on the testing scores and how to do all that. 'Cause every test is a little different and if you think you know how to do one, you'll end up with the wrong score on another.

Another participant stated:

I would also say print out the protocols. I just wrote on paper and I wish I would have written it out, or printed it out, so I was able to do the test how it was supposed to be.

I say keep their own data, too, on top of all of those. Don't just go with what you see on there. Notice everything. Take into account all of what you see if it's a real video.

\section{Discussion}


ASHA's allowance of the use of simulated experiences has encouraged the use of this medium in CD programs as an accepted method of clinical simulation hours (Dudding \& Nottingham, 2018). The purpose of this study was to determine students' perceptions of learning through simulated experiences and the supplemental activities associated with the experience in order to recognize the strengths and limitations of the experience. Through the interviews, multiple themes emerged, and they are confirmed in previous simulation and education literature. Ellis (2017) determined that students felt they would benefit the most from more real-life occurrences that forced them to think more deeply about decisions being made. Similarly, participants in the current study reported on the lack of behavioral modifications and felt that it made the experience harder to relate to. Additionally, literature supports the notion that completing real-life practices during students' courses results in increased learning outcomes (Barron et al., 2011; Blumenfeld et al., 1991; Marbouti et al., 2018). McGaghie and colleagues (2009) recommended integrating simulation-based education into the curriculum with other educational activities. The current study echoes Dudding and Nottingham's (2018) discovery that it is important to apply what is being taught in the classroom to clinical skills. Within the current study, students reported the use of computer-based simulations would allow for more concrete knowledge of experiences and to demonstrate clinical competencies. A similar argument has been made in the nursing literature due to multiple factors that impact competency assessments such as clinical site challenges, high student-faculty ratios, subjective nature of clinical evaluation, need to evaluate multiple domains, and legal considerations due to ensuring safety and competency of the student clinician (Leigh et al., 2016). These factors are often present in CD programs which reinforces the notion that computer-based simulation is a fair and appropriate measure to document the knowledge and skills of students.

To maximize the benefit of computer-based simulation, students noted the possibility to click through the simulation which is a limitation of computer-based simulation and asynchronous learning. Lew \& Nordquist (2016) researched the use of asynchronous learning in fourth-year medical students. The results of Lew and Nordquists' investigation showed that most of the students preferred asynchronous learning, but less than $25 \%$ of the students viewed all the assigned modules. The participation did not influence performance on the learning posttest evaluations. The students in the current investigation alluded to "clicking through" the responses which would be like not viewing the total content. Based on this comment, instructors should capitalize on observations and clinical interpretations throughout the simulation instead of relying only on end results to encourage and monitor participation.

Results from the current study were consistent with some of the findings in the research by Clinard and Dudding (2019) and Ellis (2017). The participants in all three studies reported limited feedback from computer-based simulation programs. McGaghie and colleagues' (2009) systematic review indicated that feedback is historically the most critical component of simulation and best educational practice. According to Kolb and Kolb (2005), given that the field of speech pathology relies heavily on clinical practice, it is best to focus higher education learning on a process that allows students to receive consistent feedback. Because of this perceived limitation, instructors should be conscious of this weakness and compensate for the lack of feedback during the debriefing process. 
Previous literature has stated the debriefing portion of a simulated experience provides students with the most learning (Putter-Katz et al., 2018; Shinnick et al., 2011). Findings were concurrent with this study as participants stated the debriefing process allowed them to ask questions, work with peers, and further increase clinical skills. Through the debriefing experience, clinical instructors have the opportunity to guide the student in reflective practice. An example of this is the use of the gather, analyze, and summarize process that was utilized for the exploration of psychometric properties (Cheng et al., 2012). Cunningham et al., (2019) identified that there is often disagreement regarding the psychometric properties of assessments. The level of disagreement may be associated with allied health professionals' knowledge and education about assessments and outcome measures (Duncan \& Murray, 2012). During the current study, students reported benefit from interpreting psychometric properties through a guided process. This technique may be easily modified in other simulated experiences to decrease the knowledge gap in this area.

Overall, students reported a positive increase in assessment knowledge which is consistent with the findings by Labrague et al., (2019) that simulation increases self-confidence which was one of the primary outcomes of the simulated clinical experience. Experiential learning is the process of utilizing experiences to transform into knowledge (Kolb, 2015). Multiple themes emerged that alluded to the notion that simulation may serve as a vehicle for knowledge with appropriate support.

Limitations. The student perceptions noted in this study cannot be generalized to other simulated experiences such as intervention or adult simulations. Additionally, the results cannot be generalized to other modalities of stimulation. Another limitation is the potential bias of the authors due to personal involvement in the simulated course.

\section{Conclusion}

Upon analysis of the interviews, it was determined that participants presented with positive and negative perceptions of the simulated experience. Participants exhibited similar thoughts and feelings across the two focus groups. The results of this study positively favored the debriefing component and the emphasis on psychometric properties. Participants reported increased understanding of test manuals and interpreting test results. As for the negative findings, students reported that the simulated platform lacked sufficient feedback and authenticity as it relates to capturing the behavioral aspects of assessments. Future research should be aimed at developing simulation curriculum in order to develop sound instructional techniques with perceived student benefit. A second future research item would be to evaluate the student perception of adult- and intervention-focused simulated cases to explore the authenticity of these cases. Research should continue to monitor student perceptions of simulated experiences in order to assess if student perception matches student performance. 


\section{Disclosures}

Regarding financial disclosures, the first author is a paying member of Simucase. The second author receives a free faculty account from Simucase. As for non-financial disclosures, both authors are affiliated with the university. The first author is a student in the communication disorders program, and the second author is a full-time faculty member and served as the instructor for the simulated experience. 


\section{References}

American Speech-Language-Hearing Association. (n.d.-a) 2020 certification standards in speech-language pathology. https://www.asha.org/Certification/2020-SLP-CertificationStandards/

American Speech-Language-Hearing Association. (n.d.-b) Certification standards for speechlanguage pathology frequently asked questions: Clinical simulation. https://www.asha.org/Certification/Certification-Standards-for-SLP--Clinical-Simulation/

American Speech-Language-Hearing Association. (2016a). Code of ethics. Available from www.asha.org/policy/.

American Speech-Language-Hearing Association. (2016b). Highlights and trends: Member and affiliate counts, year-end 2016 counts. https://www.asha.org/uploadedFiles/2016Member-Counts.pdf

American Speech-Language-Hearing Association. (2017). Issues in ethics: Cultural and linguistic competence. https://www.asha.org/Practice/ethics/Cultural-and-Linguistic-Competence/

American Speech-Language-Hearing Association. (2019). 2019 SLP health care survey: Summary report, number and type of responses. https://www.asha.org/uploadedFiles/2019-SLP-HC-Survey-Summary-Report.pdf

Barron, B. J. S., Schwartz, D. L., Vye, N. J., Moore, A., Petrosino, A., Zech, L., \& Bransford, J. D. (2011). Doing with understanding: Lessons from research on problem and projectbased learning. Journal of the Learning Sciences, 7(3\&4), 271-311. https://doi. org/10.1080/10508406.1998.9672056

Blumenfeld, P. C., Soloway, E., Marx, R. W., Krajcik, J. S., Guzdial, M., \& Palincsar, A. (1991). Motivating project-based learning: Sustaining the doing, supporting the learning. Educational Psychologist, 26(3\&4), 369-398.

Bressmann, T., \& Eriks-Brophy, A. (2012). Use of simulated patients for a student learning experience on managing difficult patient behavior in speech-language pathology contexts. International Journal of Speech-Language Pathology, 14(2), 165-173.

Brydon, M. (2018). Guidance document to accompany "On standardized assessment". The Informed SLP.

https://www.theinformedslp.com/uploads/1/0/7/9/10794678/standardized_assessment_ev al.pdf

Carpenter, C. \& Suto, M. (2008). Qualitative research for occupational and physical therapists. Blackwell Publishing. 
Cheng, A., Rodgers, D. L., Van Der Jagt, D., Eppich, W., \& O'Donnell, J. (2012). Evolution of the pediatric advanced life support course: Enhanced learning with a new debriefing tool and web-based module for pediatric advanced life support instructors. Pediatric Critical Care Medicine, 13(5), 589-595.

Clinard, E. S., \& Dudding, C. C. (2019). Integrating simulations into communication sciences and disorders clinical curriculum: Impact of student perceptions. American Journal of Speech-Language Pathology 28(1), 136-147.

Cummings, C. L., \& Connelly, L. K. (2016). Can nursing students' confidence levels increase with repeated simulation activities? Nurse Education Today, 36, 419-421.

Cunningham, B. J., Daub, O. M., \& Cardy, J. O. (2019) Barriers to implementing evidence-based assessment procedures: Perspectives from the front lines in pediatric speech-language pathology. Journal of Communication Disorders, 80, 66-80.

CVi Security. (2017). Clinical observation recording system (CORS). [Computer software]. http://www.cvisecurity.com/solutions/clinical-observation-recording-system/

Dudding, C. C., \& Nottingham, E. E. (2018). A national survey of simulation use in university programs and communication sciences and disorders. American Journal of SpeechLanguage Pathology. 27(71-81).

Duncan, E., \& Murray, J. (2012). The barriers and facilitators to routine outcome measurement by allied health professionals in practice: A systematic review. BMC Health Services Research, 12, Article 96. https://bmchealthservres.biomedcentral.com/articles/10.1186/1472-6963-12-96

Ellaway, R., Poulton, T., Fors, U., McGee, J. B., \& Albright, S. (2008). Building a virtual patient commons. Medical Teacher, 30(2), 170-174.

Ellis, C. M. (2017). Using simulation and critical thinking in speech-language pathology: A university case study. Journal of Human Services: Training, Research, and Practice. 2(2), Article 6.

Fitzgerald, K., Denning, T., \& Vaughan, B. (2017). Simulated learning activities as part replacement of clinical placements in osteopathy: A case study. International Journal of Osteopathic Medicine, 26, 44-48. https://doi.org/10.1016/j.ijosm.2017.10.003

Foley, M. E., Nespoli, G., \& Conde, E. (1997). Using standardized patients and standardized physicians to improve patient-care quality: Results of a pilot study. Journal of Continuing Education in Nursing, 28, 198-204.

Glesne, C. (2016). Becoming qualitative researchers: An introduction (5th ed.). Pearson. 
Ha, E-H. (2018). Experience of nursing students with standardized patients in simulation-based learning: Q-methodology study. Nurse Education Today, 66, 123-129.

Howard, V. M., Englert, N., Kameg, K., \& Perozzi, K. (2011). Integration of simulation across the undergraduate curriculum: Student and faculty perspectives. Clinical Simulation in Nursing, 7, e1-e10.

Jansen, L. J., Johnson, C., Ondo, K., Pantalone, B., \& Williams, S. L. (2015). Simucase: Case by case. Improving clinical skills. Inspiring confidence: User guide 3.0. www.speechpathology.com.

Johns Hopkins Medical Simulation Center (2018). Partial task models. Johns Hopkins Medicine. https://www.hopkinsmedicine.org/simulation_center/training/mannequin_based_simulati ons/partial_task_models.html

Johnson, C., Jansen, L. J., Ondo, K., Williams, S. L., Pantalone, B. (2019). Simucase: Creating connections. Inspiring confidence: User guide 3.0. www.speechpathology.com

Kolb, A. Y., \& Kolb, D. A. (2005). Learning styles and learning spaces: Enhancing experiential learning in higher education. Academy of Management Learning \& Education, 4(2), 193212.

Kolb, D. A. (2015). Experiential learning: Experience as the source of learning and development (2nd ed.). Pearson.

Labrague, L. J., McEnroe-Petitte, D. M., Bowling, A. M., Nwafor, C. E., \& Tsaras, K. (2019). High-fidelity simulation and nursing students' anxiety and self-confidence: A systematic review. Nursing Forum, 54(3), 358-368.

Lateef, F. (2010). Simulation based learning: Just like the real thing. Journal of Emergencies, Trauma, and Shock, 3(4), 348-352.

Leigh, G., Stueben, F., Harrington, D., \& Hetherman, S. (2016). Making the case for simulationbased assessments to overcome the challenges in evaluating clinical competency. International Journal of Nursing Education and Scholarship, 13(1), 1-8.

Lew, E. K., \& Nordquist, E., K. (2016). Asynchronous learning: Student utilization of synch with their preference. Medical Education Online, 21(1).

Marbouti, F., Shafaat, A., Ulas, J., \& Diefes, D. H. A. (2018). Relationship between time of class and student grades in an active learning course. Journal of Engineering Education, 107(3), 468-490. https://doi-org.cyrano.ucmo.edu/10.1002/jee.20221

McGaghie, W. C., Siddall, V. J., Mazmanian, P. E., \& Myers, J. (2009). Simulation in undergraduate and graduate medical education: Implications for CME. Chest, 135(3 Suppl.), 62S-68S. 
Miles, A., Frairy, P., Jackson, B., Sekula, J., \& Braakhuis, A. (2016). Simulation-based dysphagia training: Teaching interprofessional clinical reasoning in a hospital environment. Dysphagia, 31, 407-415.

Milne, A., Johnson J. A., Tennant, M., Rudnisky, C., \& Dryden, D. M. (2012). Measuring health-related quality of life for patients with diabetic retinopathy. Agency for Healthcare Research and Quality. https://pubmed.ncbi.nlm.nih.gov/25356446/

Nehring, W. M., Lashley, F. R., \& Ellis, W. E. (2002). Critical incident nursing management using human patient simulators. Nursing Education Perspectives, 23(3), 128-132.

Putter-Katz, H., Gvion, A., Wechsler-Kashi, D., Said, L. A-B., Yaacobi, H., Feldman, I., Shalomson, O., \& Amitai, Z. (2018). Students' evaluation of simulation-based training in a communication sciences and disorders program. Journal of Allied Health, 47(2), 113120.

Sawyer, T., Eppich, W., Brett-Fleegler, M., Grant, V., \& Cheng, A. (2016). More than one way to debrief: A critical review of healthcare simulation debriefing methods. Simulation in Healthcare: Journal of the Society for Simulation in Healthcare, 11(3), 209-217.

Scherer, Y. K., Foltz-Ramos, K., Fabry, D., \& Chao, Y-Y. (2016). Evaluating simulation methodologies to determine best strategies to maximize student learning. Journal of Professional Nursing, 23(5), 349-357.

Shinnick, M. A., Woo, M., Horwich, T. B., \& Steadman, R. (2011). Debriefing: The most important component in simulation? Clinical Simulation in Nursing, 7(3), e105-e111.

Simucase. (2019). [Computer software]. https://simucase.com/

Ward, E. C., Hill, A. E., Nund, R. L., Rumbach, A. F., Walker-Smith, K., Wright, S. E., Kelly, K., \& Dodrill, P. (2015). Developing clinical skills in pediatric dysphagia management using human patient simulation (HPS). International Journal of Speech-Language Pathology. 17(3): 230-240.

Wildman, S., \& Reeves, M. (1997). The value of simulations in the management education of nurses: Students' perceptions. Journal of Nursing Management, 5, 207-215.

Wilkerson, W., Avstreih, D., Gruppen, L., Beier, K-P., \& Woolliscroft, J. (2008). Using immersive simulation for training first responders for mass casualty incidents. Academic Emergency Medicine, 15(11), 1152-1159. 


\section{Appendix A}

Part I: General Perceptions of the Course:

1. Tell me about your overall experience with the Summer, 2019 clinical course.

a. What elements of the experience did you find particularly interesting or meaningful?

b. What did you find most challenging?

c. What about this course would you change for future students?

d. What piece of advice would you give to a student preparing to take this course?

Part II: The Simucase Experience:

2. Describe the simulated training you received with Simucase.

a. What elements of the experience did you find most enjoyable?

b. What elements were most challenging or difficult?

3. Tell me about the feedback you received during the simulated experience.

4. What would make that feedback more effective?

a. What elements of the simulation experience would you say were the least beneficial to you?

5. Describe the process of pre-briefing and debriefing.

a. Why did you find this process to be helpful or unhelpful?

b. What might you change to make this process more effective for future students?

6. How would you describe the strategies you used to be successful during the simulated experience?

a. What strategies would you recommend to others to help them succeed?

b. What elements of the course do you believe helped you succeed during the experience?

i. What elements of the course could have been improved to help you be more successful?

7. Describe how the instructor played a role in your overall Simucase training experience

a. What did the instructor do that was particularly helpful for your learning?

b. What resources, materials, or support from the instructor would have improved your experience?

Part III: Perceived Learning as a result of Simucase:

8. Tell me about whether or not you believe the Simucase experience helped prepare you for a career in speech pathology.

a. What do you believe you learned as a result of the simulation?

b. How do you expect this experience might impact your clinical placements or education in general?

c. Reflect on your confidence level before and then after your experience with Simucase

i. Do you feel like you better understand test administration, scoring, and analysis?

ii. Is there anything else you would like to share with me that we have not covered? 